\title{
Syringomyelia in children with closed spinal dysraphism: long-term outcomes after surgical intervention
}

\author{
Amy K. Bruzek, MD, MS, ${ }^{1}$ Jordan Starr, MD, ${ }^{1}$ Hugh J. L. Garton, MD, MHSc, ${ }^{1}$ \\ Karin M. Muraszko, MD, ${ }^{1}$ Cormac O. Maher, MD, ${ }^{1}$ and Jennifer M. Strahle, MD ${ }^{2}$ \\ 'Department of Neurosurgery, University of Michigan, Ann Arbor, Michigan; and 2Department of Neurosurgery, Washington \\ University School of Medicine, St. Louis, Missouri
}

\begin{abstract}
OBJECTIVE The nature of the relationship between spinal cord syrinx and tethered cord is not well known. It is unclear if surgical cord untethering results in resolution or improvement of an associated syrinx. The objective of this study was to report the response of spinal cord syrinx to surgical cord untethering.

METHODS The authors retrospectively reviewed all patients with a syrinx and tethered cord who presented to a single institution over an 11-year interval. Patients with open neural tube defects were excluded. Thirty-one patients were identified, 25 of whom had both clinical and imaging follow-up after surgery. Patients were grouped according to etiology of the tethered cord. Clinical outcomes and syrinx characteristics were recorded.

RESULTS Of the 25 patients with tethered cord, $68 \%(n=17)$ were male. The average age at presentation was 2.5 years (0-10.1 years) and age at surgery was 3.7 years (range 1 day to 17 years). Etiologies of tethered cord were lipomyelomeningocele $(n=8)$, thickened/fatty filum $(n=7)$, intradural lipoma $(n=5)$, myelocystocele $(n=2)$, meningocele ( $n$ $=2$ ), and diastematomyelia $(n=1)$. Twenty-three of the patients underwent primary untethering, whereas 2 patients had received untethering previously at another institution. The average syrinx length and width prior to surgery were 4.81 vertebral levels (SD 4.35) and $5.19 \mathrm{~mm}(\mathrm{SD} 2.55 \mathrm{~mm})$, respectively. Conus level ranged from L1 to S3. Patients were followed for an average of 8.4 years (1.35-15.85 years). Overall there was no significant change in syrinx length or width postoperatively; the average syrinx length increased by 0.86 vertebral levels (SD 4.36) and width decreased by $0.72 \mathrm{~mm}$ (SD $2.94 \mathrm{~mm}$ ). Seven of 25 patients had improvement in at least one presenting symptom, including scoliosis, weakness, bowel/bladder dysfunction, and pain. Eight patients had stable presenting symptoms. Six patients were asymptomatic and 5 patients had new or worsening symptoms, which included scoliosis, pain, or sensory changes.
\end{abstract}

CONCLUSIONS Although some syrinxes improved after surgery for tethered cord, radiological improvement was not consistent and did not appear to be associated with change in clinical symptoms. The decision to surgically untether a cord should be focused on the clinical symptoms and not the presence of a syrinx alone. Further studies are needed to confirm this finding.

https://thejns.org/doi/abs/10.3171/2019.9.PEDS1944

KEYWORDS syrinx; tethered cord; spinal dysraphism; spine; congenital

S YRINGOMYELIA is frequently associated with concurrent craniocervical junction or intraspinal pathology. ${ }^{14}$ In the case of patients with Chiari I malformation, a syrinx may lead to a recommendation for surgical treatment, ${ }^{12}$ because there is a clear pathophysiological relationship between altered CSF flow at the foramen magnum and development of a spinal cord syrinx. ${ }^{11}$ Approximately $12 \%$ of syrinxes are associated with tethered cord in the absence of open neural tube defects, such as those associated with lipomyelomeningocele (LMMC), intradural lipoma, and thickened/fatty filum. ${ }^{14}$ Although the association between cord tethering and syrinx is recognized, it is not known if there is a direct pathophysiological relationship. In a study of pediatric patients with tethered cord syndrome without significant imaging abnormalities such as LMMC, lipoma, or thickened/fatty filum terminale, the majority of patients displayed no change in syrinx size after surgery. ${ }^{8}$ It is unknown how surgical intervention for

ABBREVIATIONS LMMC = lipomyelomeningocele.

SUBMITTED June 6, 2019. ACCEPTED September 10, 2019.

INCLUDE WHEN CITING Published online December 13, 2019; DOI: 10.3171/2019.9.PEDS1944. 
other tethered cord pathologies affects syrinx width or length.

Here we report long-term follow-up of syrinx and clinical symptoms in a cohort of patients with tethered cord and syrinx who were surgically treated for their tethered cord.

\section{Methods}

Following institutional review board approval, all patients $(\leq 18$ years old) with both a syrinx and closed spinal dysraphism were identified from a group of 14,118 consecutive patients who underwent brain or cervical spine MRI over an 11-year interval at the University of Michigan. All patients with a syrinx and closed spinal dyraphism were identified. Exclusion criteria included the following: 1) Chiari malformation with surgical decompression, and 2) patients with open spinal dysraphism due to the high frequency of Chiari II malformation and hydrocephalus in this group, which may also be associated with syrinx. Of the 35 patients identified, 10 were excluded; 9 did not have MRI of the spine following surgery, and 1 patient was ultimately found to have had a prior posterior fossa decompression for Chiari I malformation. Charts were reviewed for clinical and imaging characteristics pre- and postoperatively. Twenty-five patients met inclusion criteria with tethered cord pathology, including LMMC $(n=8)$, thickened/fatty filum terminale $(n=7)$, intradural lipoma $(n=5)$, meningocele $(n=2)$, myelocystocele $(n=2)$, and diastematomyelia $(\mathrm{n}=1)$. In considering primary versus secondary untethering, 2 patients underwent LMMC repair previously and 2 patients had untethering prior to presentation at our institution. For the 2 patients who had untethering prior to presenting to our hospital, both had syrinx noted prior to primary untethering. However, imaging was unavailable for review to determine syrinx size at initial presentation. The remaining 21 patients received primary untethering at our institution.

Syrinx was defined as a spinal cord cyst at least $3 \mathrm{~mm}$ in axial width that was hyperintense on T2-weighted MRI and hypointense on T1-weighted MRI. For each patient, the length of the syrinx was defined by the number of vertebral levels. Change in syrinx was defined as an increase or decrease in length or width of 1 vertebral level or $1 \mathrm{~mm}$, respectively. Scoliosis was defined as a coronal curve with Cobb angle of at least $10^{\circ}$. An improvement in scoliosis was defined as a decrease in curve magnitude of $\geq 10^{\circ}$, and scoliosis worsening was defined as an increase in curve magnitude of $\geq 10^{\circ}$. Patients who had multiple types of spinal dysraphism were included only in the group representing their primary pathology for untethering.

\section{Results}

\section{Patient Characteristics}

Twenty-five patients met inclusion criteria, of whom 17 $(68 \%)$ were male (Table 1). The average age at presentation was 2.47 years (range 1 day-10.1 years), and the average age at surgery was 3.66 years (range 1 day-17 years) (Table 2). The average follow-up duration was 8.42 years (range 1.35-15.85 years).

Clinical indications for surgery included prophylactic
TABLE 1. Demographics in 25 patients with tethered cord and syrinx

\begin{tabular}{lc}
\hline \multicolumn{1}{c}{ Characteristic } & Value \\
\hline Sex (\%) & $17(68 \%)$ \\
\hline Male & $8(32 \%)$ \\
\hline Female & $2.47(0-10.14)$ \\
\hline Average age in yrs (range) & $11(44 \%)$ \\
\hline Clinical presentation (\%) & $8(32 \%)$ \\
\hline Scoliosis & $8(32 \%)$ \\
\hline Back or leg pain & $4(16 \%)$ \\
\hline Urinary/bowel dysfunction & $2(8 \%)$ \\
\hline Lower-extremity weakness & 11 \\
\hline Sensory disturbance & 9 \\
\hline Indication for untethering & 4 \\
\hline Prophylactic & 4 \\
\hline Symptomatic worsening or neurological decline & \\
\hline Scoliosis & 8 \\
\hline Syrinx & 7 \\
\hline Pathology for untethering & 5 \\
\hline LMMC & 2 \\
\hline Thickened/fatty filum & 2 \\
\hline Lipoma & 1 \\
\hline Myelocystocele & \\
\hline Meningocele & \\
\hline Diastematomyelia & \\
\hline
\end{tabular}

untethering to protect against future neurological symptoms or decline $(\mathrm{n}=11)$, worsening neurological symptoms or deficits $(n=9)$, scoliosis $(n=4)$, and terminal syrinx ( =4) (Table 1). Some patients had multiple, equivalent indications for surgery. Among the patients with worsening symptoms or deficits, clinical symptoms included progressive extremity weakness or numbness $(n=5)$, worsening pain $(n=3)$, progressive bowel or bladder dysfunction $(n=$ $2)$, increased spasticity $(n=1)$, and difficulty with ambulation $(\mathrm{n}=1)$.

In addition to syrinx size, clinical symptoms were evaluated prior to and after surgery. Patients were considered symptomatic if they had scoliosis, urinary or bowel dysfunction, back or leg pain, numbness/tingling, or gait abnormalities. At initial presentation, 15 patients were symptomatic, including scoliosis $(\mathrm{n}=11)$, back or leg pain $(\mathrm{n}=$ $8)$, urinary or bowel dysfunction $(n=8)$, motor deficits $(n=$ $4)$, and numbness/tingling $(n=2)$. At initial presentation, 11 of 25 patients had scoliosis and 6 underwent spinal fusion either at the time of $(n=3)$ or after cord untethering $(n=3$, average of 3.6 years [range 1.53-7.16 years]). Initial syrinx length ranged from 1 vertebral level to 19 vertebral levels, and the greatest width of the syrinx ranged from $3 \mathrm{~mm}$ to $13 \mathrm{~mm}$ (mean width $5.19 \mathrm{~mm}$, SD 2.54). Syrinx locations ranged from $\mathrm{C} 4$ to the conus. The cranial-most syrinx extent prior to surgery ranged between $\mathrm{C} 4$ and $\mathrm{T} 7$, and the caudal extent prior to surgery was between C6 and S2.

When stratified by pathology, patients with LMMC had a cranial extent of the syrinx that ranged between $\mathrm{C} 4$ and 


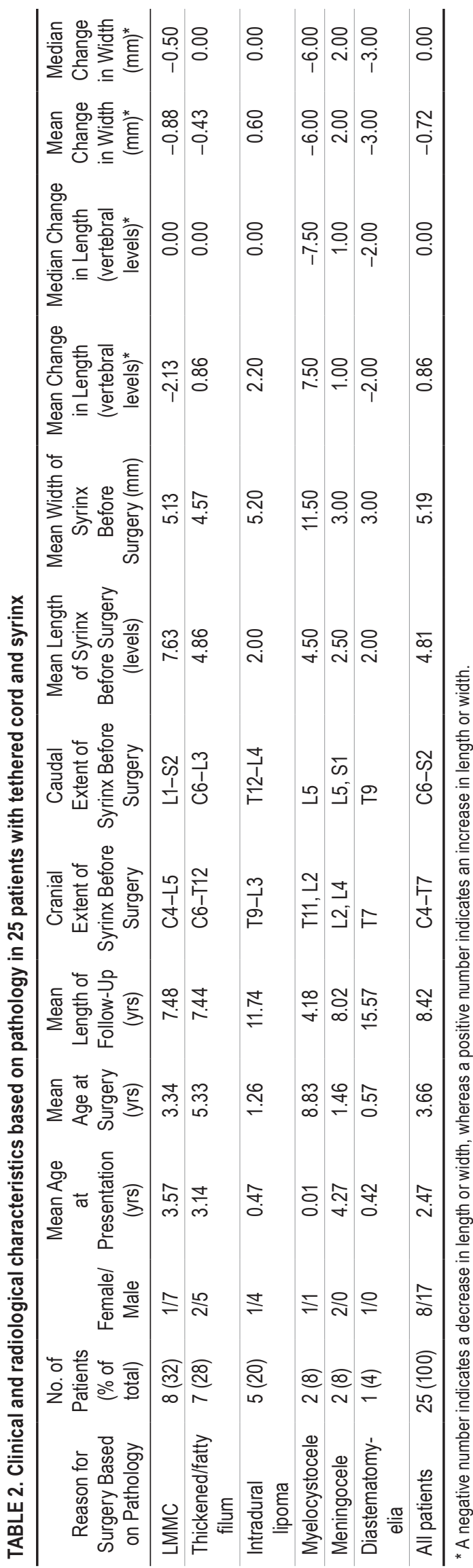

L5, and a caudal extent that ranged between L1 and S2 (Figs. 1 and 2). For the patients with thickened/fatty filum, cranial extent ranged from C6 to T12, with cranial extent of syrinx to C6 in 1 patient and T5 or below in the remaining 6 patients; caudal extent ranged from C6 to L3. Patients with intradural lipomas had cranial extent between T9 and L3, and caudal extent between T12 and L4. The cranial extents for the patients with myelocystocele were T11 and L2, and the caudal extent was L5 for both patients. For the 2 patients with meningoceles, the cranial extents were L2 and L4, and caudal extents were L5 and S1. The 1 patient with diastematomyelia had a syrinx that extended from T7 to T9 (Table 2).

\section{Change in Syrinx Size After Untethering Surgery}

After surgery, the average change in length of the syrinx across all patients was an increase of 0.86 vertebral levels (SD 4.36 levels, $p=0.50$ ) with a median change of 0 levels, and the average change in width was a decrease of $0.72 \mathrm{~mm}$ (SD $2.94 \mathrm{~mm}, \mathrm{p}=0.06$ ) with a median change of $0 \mathrm{~mm}$. Nine of $25(36 \%)$ patients had improvement in syrinx size, 12 (48\%) had no net change in syrinx size, and $4(16 \%)$ had an increase in syrinx dimensions in length and width (Fig. 1). The average follow-up between surgery and the most recent MRI was 8.42 years (range 1.35-15.85 years). There was no relationship between change in syrinx and length of follow-up.

When evaluating the change in syrinx size based on pathology as reason for untethering, the patients with myelocystocele had the largest change in syrinx dimensions, with an average decrease in width of $6 \mathrm{~mm}$ and an increase in length of 7.5 levels. The patients with intradural lipoma and meningocele had an increase in both length and width of their syrinxes, whereas patients with diastematomyelia and LMMC had a decrease in both length and width of their syrinxes (Table 3, Fig. 2).

In considering other pathology that may be amenable to detethering, we excluded patients with open spinal dysraphism, Chiari malformation, or untreated hydrocephalus. Two of our patients had ventriculoperitoneal shunts; one had an increase in the syrinx length and the other had a decrease in the syrinx length.

\section{Clinical Improvement After Untethering}

There was no clear relationship between syrinx resolution/progression and symptomatic improvement after surgery. Seven patients presented with back or leg pain, only 2 of whom had improvement of their pain; 1 of the 2 patients had a decrease in size of the syrinx (by 6 vertebral levels in length and $1 \mathrm{~mm}$ in width) and the other had no change in size (increase in length by 7 vertebral levels, decrease in width by 1 millimeters). Of the 5 patients with unchanged or new back or leg pain at follow-up, 2 had improvement of their syrinx and 3 had no change in syrinx size. Three of 7 patients who presented with urinary or bowel dysfunction had improvement after untethering, 2 of whom had improvement in syrinx size. Only 1 of the 5 patients with a motor deficit (including gait abnormality) had improvement in symptoms, and that patient also had improvement in the syrinx. All 4 patients with sen- 

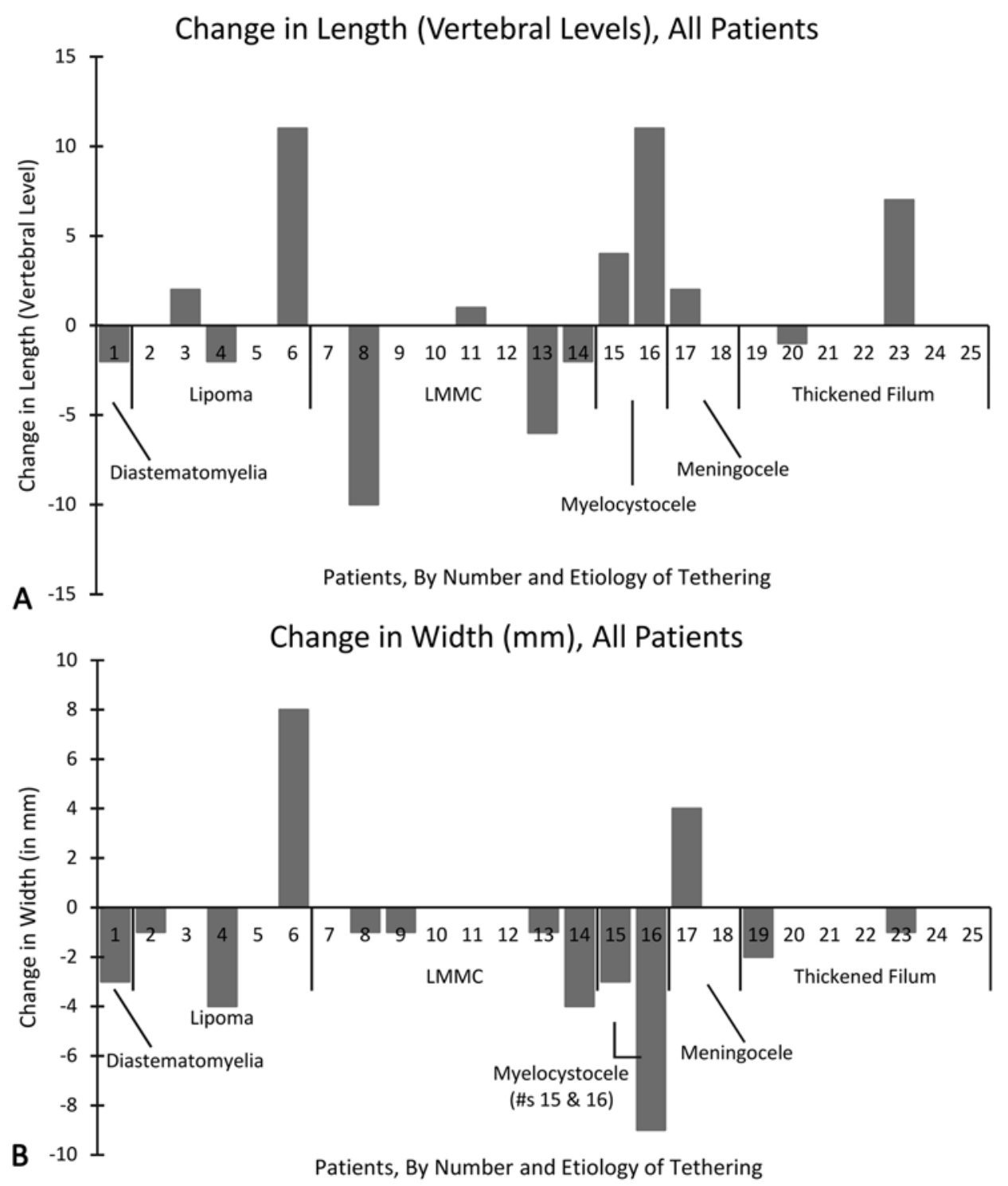

FIG. 1. Bar graphs showing change in (A) length (number of vertebral levels) and (B) width (in millimeters) of syrinx for each patient $(n=25)$.

sory disturbance (including numbness or tingling) had unchanged or worse symptoms at follow-up and no syrinx improvement (Table 3).

In examining the relationship between scoliosis and syrinx size, 4 of the 6 patients who underwent fusion ultimately had improvement in scoliosis and 2 did not. Three patients had a fusion at the time of untethering, 2 of whom ultimately had improvement in scoliosis (ages 2.79 and 14.28 years at time of surgery) and 1 of whom did not (age 5.86 years at time of surgery). Of the patients who underwent surgical correction for scoliosis, 3 had improvement of syrinx size, 2 had no change in syrinx size, and 1 patient had an increase in length and a decrease in width. None of the 5 patients who did not have a fusion had improvement of their scoliosis. Of those patients, 2 had improvement in the size of their syrinx, 1 had an increase in both length and width, and 2 had no change in syrinx size (Table 3).

\section{Discussion}

For this study, we evaluated closed spinal dysraphism, because there is frequently concurrent Chiari II malformation and hydrocephalus in patients with open spinal dysraphism, which makes evaluation of syringomyelia even more complex due to multiple potential etiologies. Whereas the relationship of spinal cord syrinx to its primary pathology is well understood in some cases (Chiariassociated syrinx), it is not well known how spinal cord syrinxes respond to surgical intervention for tethered cord. ${ }^{11}$ The goal of this study was to report long-term outcomes for patients with syrinxes who underwent either a primary or secondary untethering operation for closed spinal dysraphism. In our cohort of 25 patients with syrinxes who underwent cord untethering, there was no consistent radiological improvement in the presence or size 


\section{Change in Length of Syrinx By Pathology}

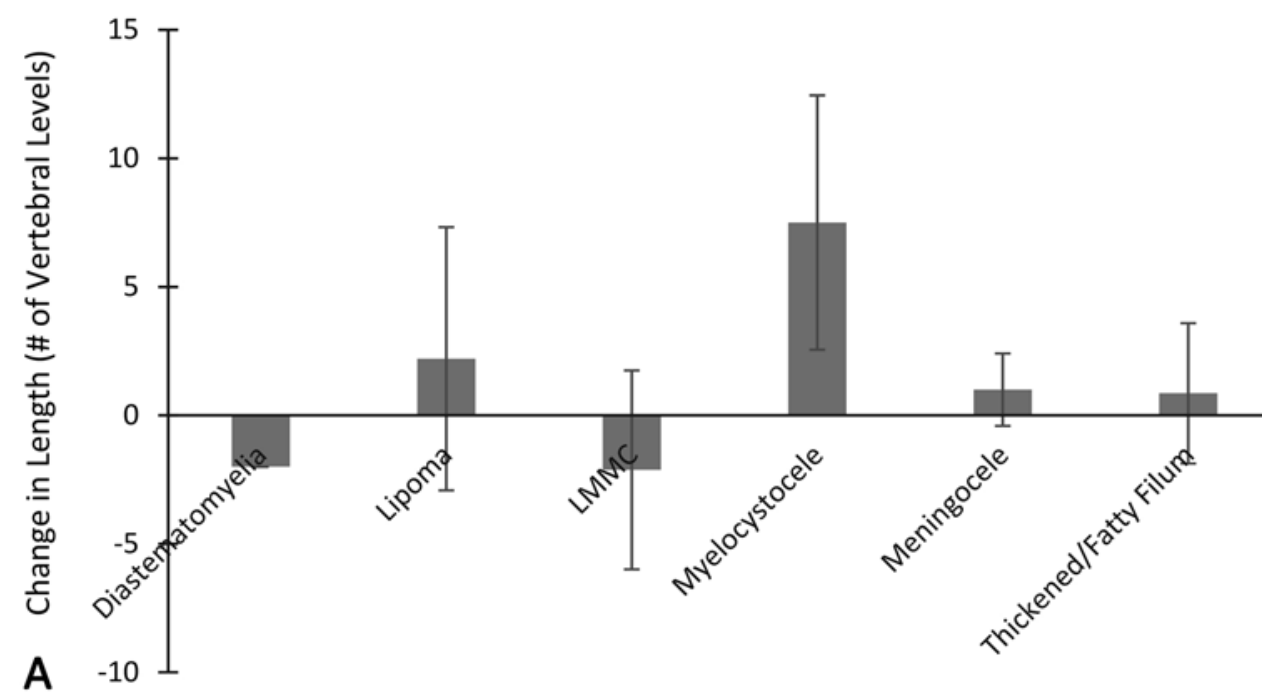

Change in Width of Syrinx By Pathology

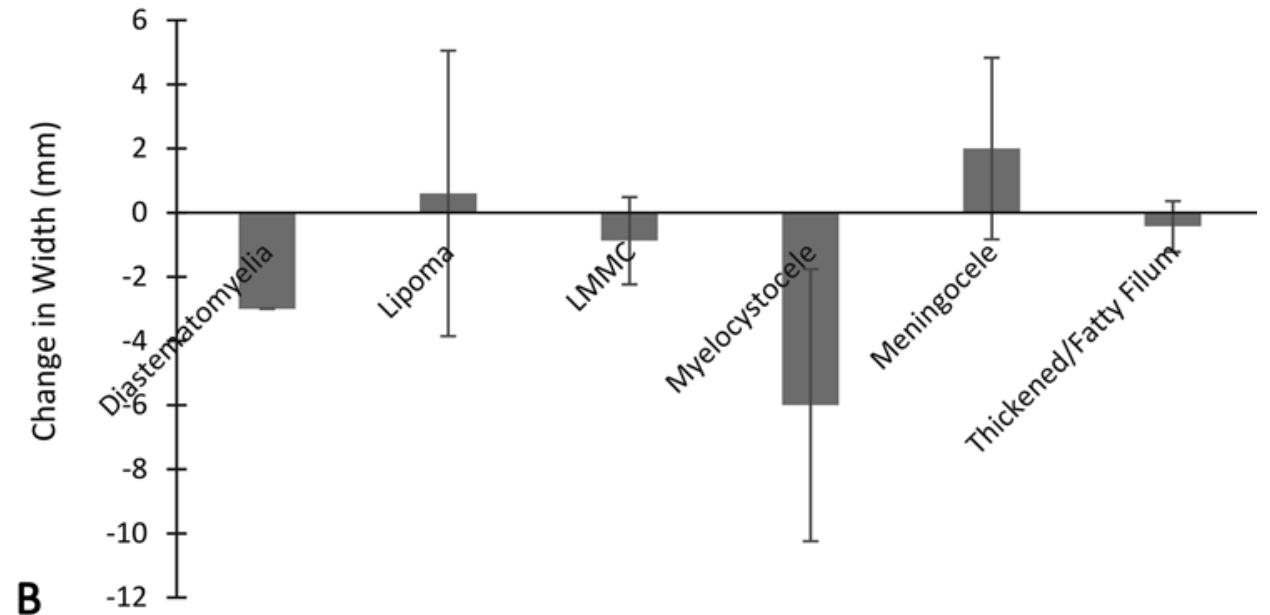

FIG. 2. Bar graphs showing change in (A) length (number of vertebral levels) and (B) width (maximum axial width in millimeters) of syrinx by pathology.

of the syrinx following surgery. Furthermore, change in syrinx size, whether it was an increase or decrease in size, was not associated with clinical outcome.

A spinal cord syrinx may occur in the setting of craniocervical junction pathology such as Chiari malformations, open and closed spinal dysraphism, or thickened/fatty filum, and in many cases it is considered idiopathic, because it is seen in isolation with no clear associated pathology. ${ }^{14}$ In the case of syrinx and Chiari I malformation, the established relationship between the syrinx and tonsil position is clear and treatment decisions are frequently made based on the presence of a syrinx alone. , $^{2,11,12}$ However, the relationship of a spinal cord syrinx identified on imaging to the presence of intraspinal pathology resulting in a tethered cord is not well understood. In some cases the syrinx is a result of primary spinal cord development in the setting of dysraphic pathology that results in a cavita- tion; ${ }^{5}$ untethering in these cases would not be expected to alter the spinal cord syrinx. However, there could be cases of symptomatic tethering that result in a spinal cord syrinx, possibly through distension of the cavity secondary to adherence of the spinal cord and/or nerve roots to the surrounding tissues. Finally, it is possible that a subset of syrinxes are idiopathic and unrelated to the cord tethering.

Tethered cord syndrome is a clinical diagnosis seen in patients with a low-lying conus, secondary to various pathologies, including LMMC, diastematomyelia, thickened/fatty filum, intradural lipoma, etc. The decision to surgically untether the cord is generally guided by symptoms of cord tethering or prophylactic prevention of future tethering. Twelve percent of patients with syrinx have associated lumbosacral pathology of the kind typically seen in the setting of tethered cord. ${ }^{14}$

In a series of 16 patients with minimal radiological 
TABLE 3. Change in syrinx size versus clinical symptoms in 25 patients with tethered cord and syrinx

\begin{tabular}{|c|c|c|c|c|c|}
\hline Factor & $\begin{array}{c}\text { Syrinx } \\
\text { Improvement }\end{array}$ & $\begin{array}{c}\text { Syrinx } \\
\text { Unchanged }\end{array}$ & $\begin{array}{l}\text { Syrinx Increased in } \\
\text { Both Length and Width }\end{array}$ & $\begin{array}{l}\text { Syrinx Increased in Length, } \\
\text { Decreased in Width }\end{array}$ & $\begin{array}{l}\text { Total No. } \\
\text { (\% of total) }\end{array}$ \\
\hline No. of patients & 9 & 9 & 4 & 3 & $25(100)$ \\
\hline \multicolumn{6}{|l|}{ Scoliosis w/ fusion } \\
\hline Improved & 2 & 1 & 0 & 1 & $4(16)$ \\
\hline Unchanged/worse & 1 & 1 & 0 & 0 & $2(8)$ \\
\hline \multicolumn{6}{|l|}{ Scoliosis w/o fusion } \\
\hline Improved & 0 & 0 & 0 & 0 & $0(0)$ \\
\hline Unchanged/worse & 2 & 0 & 1 & 2 & $5(20)$ \\
\hline \multicolumn{6}{|l|}{ Back or leg pain } \\
\hline Improved & 1 & 0 & 0 & 1 & $2(8)$ \\
\hline Unchanged/worse & 2 & 3 & 0 & 0 & $5(20)$ \\
\hline \multicolumn{6}{|c|}{ Urinary/bowel dysfunction } \\
\hline Improved & 2 & 1 & 0 & 0 & $3(12)$ \\
\hline Unchanged/worse & 2 & 0 & 2 & 0 & $4(16)$ \\
\hline \multicolumn{6}{|c|}{ Gait abnormality/motor deficit } \\
\hline Improved & 1 & 0 & 0 & 0 & $1(4)$ \\
\hline Unchanged/worse & 2 & 1 & 1 & 0 & $4(16)$ \\
\hline \multicolumn{6}{|l|}{ Sensory disturbance } \\
\hline Improved & 0 & 0 & 0 & 0 & $0(0)$ \\
\hline Unchanged/worse & 0 & 2 & 1 & 1 & $4(16)$ \\
\hline Asymptomatic & 1 & 4 & 1 & 0 & $6(24)$ \\
\hline
\end{tabular}

findings, primary clinical tethered cord syndrome, and syrinx, the majority of patients had clinical improvement after untethering; however, only one-quarter had improvement in the size of their syrinx. ${ }^{8}$ Our findings are consistent with this study in that the majority of our patients had no change in syrinx size after surgery. Other groups have reported similar findings of lack of syrinx improvement or resolution after surgical treatment for tethering pathology, with 1 group reporting that all 8 patients with syrinx who underwent surgery for diastematomyelia had no change in syrinx size. ${ }^{4}$

In contrast to these prior studies, Lee et al. ${ }^{9}$ evaluated 32 patients with tethered cord secondary to lumbosacral lipoma, thickened/fatty filum, or LMMC, and these investigators reported 31 of 32 patients with resolution, stabilization, or improvement of the syrinx. Only 1 patient had enlargement of the syrinx, which was thought to be secondary to retethering. Follow-up duration was shorter in this study compared to ours, which could account for differences in observed changes in syrinx. Although unlikely, it is possible in our study that surgical intervention halted what would have been a progressive increase in syrinx size and therefore would be consistent with this report of improvement in syrinx following surgical intervention for tethered cord. In our study, the limitation in number of patients and lack of statistical significance for improvement in syrinx size over time prevents a definitive statement regarding whether there would have been a progressive increase in syrinx size.

Some groups have advocated direct drainage of the syrinx in the setting of occult spinal dysraphism, particularly in cases with large syrinxes. Iskandar et al. ${ }^{7}$ found that di- rect surgical shunting of large terminal syrinxes resulted in symptomatic improvement. Erkan et al. ${ }^{3}$ found that directly treating the syrinx in combination with cord untethering resulted in the most improvement in symptoms.

The fact that the natural history of idiopathic syringomyelia is generally benign ${ }^{10,13}$ and the apparent lack of a clear relationship between surgical intervention and change in syrinx size may suggest that syrinxes seen in the setting of occult/closed spinal dysraphism may not have a clear pathophysiological connection to tethering. In this case, the development of the spinal cord itself results in the fluid-filled cavity. ${ }^{5}$

While the association of syrinx and scoliosis is known, it is unclear how a change in syrinx size after cord untethering may or may not lead to a change in scoliosis outcome. Existing literature has examined how scoliosis changes after direct surgical intervention for syringomyelia, ${ }^{1,15,16}$ but little has been published about how scoliosis may cause a syrinx and how the syrinx may change after intervention for scoliosis. Because it is unknown how or if deformity correction affects syrinx size, we reported syrinx size in patients with scoliosis who did not undergo deformity correction as well as in those who did. In the specific setting of a spinal tethering lesion in this patient cohort, the 11 patients with both scoliosis and syrinx had no definitive improvement in syrinx size regardless of whether or not there was a scoliosis correction and fusion. Overall, there was no clear pattern between improvement in syrinx size and scoliosis.

Limitations to our study include the retrospective nature and small sample size. We are limited in drawing conclusions about how a change in syrinx size may or may not 
be associated with scoliosis because correction of scoliosis may also impact syrinx size (in addition to cord undertethering). Future studies will include patients with open spinal dysraphism, because this is an important group of patients who frequently have concurrent cord tethering and syringomyelia.

\section{Conclusions}

In patients undergoing either primary or secondary untethering procedures for closed spinal dysraphism, syrinx size did not change consistently, nor was change in syrinx size related to clinical improvement. In patients with tethered cord and syrinx, the decision to operate should focus on tethered cord-related symptoms and/or treatment of the primary spinal dysraphism rather than the presence of syrinx, as there is no clear improvement in syrinx width or length following surgery. The relationship between cord tethering and syrinx deserves further investigation.

\section{References}

1. Bradley LJ, Ratahi ED, Crawford HA, Barnes MJ: The outcomes of scoliosis surgery in patients with syringomyelia. Spine (Phila Pa 1976) 32:2327-2333, 2007

2. Clarke EC, Stoodley MA, Bilston LE: Changes in temporal flow characteristics of CSF in Chiari malformation Type I with and without syringomyelia: implications for theory of syrinx development. J Neurosurg 118:1135-1140, 2013

3. Erkan K, Unal F, Kiris T: Terminal syringomyelia in association with the tethered cord syndrome. Neurosurgery 45:1351-1360, 1999

4. Gan YC, Sgouros S, Walsh AR, Hockley AD: Diastematomyelia in children: treatment outcome and natural history of associated syringomyelia. Childs Nerv Syst 23:515-519, 2007

5. Guo A, Chitayat D, Blaser S, Keating S, Shannon P: Fetal syringomyelia. Acta Neuropathol Commun 2:91, 2014

6. Heiss JD, Patronas N, DeVroom HL, Shawker T, Ennis R, Kammerer W, et al: Elucidating the pathophysiology of syringomyelia. J Neurosurg 91:553-562, 1999

7. Iskandar BJ, Oakes WJ, McLaughlin C, Osumi AK, Tien RD: Terminal syringohydromyelia and occult spinal dysraphism. J Neurosurg 81:513-519, 1994

8. Kulwin CG, Patel NB, Ackerman LL, Smith JL, Boaz JC, Fulkerson DH: Radiographic and clinical outcome of syringomyelia in patients treated for tethered cord syndrome without other significant imaging abnormalities. J Neurosurg Pediatr 11:307-312, 2013
9. Lee JY, Phi JH, Cheon JE, Kim SK, Kim IO, Cho BK, et al: Preuntethering and postuntethering courses of syringomyelia associated with tethered spinal cord. Neurosurgery 71:2329,2012

10. Magge SN, Smyth MD, Governale LS, Goumnerova L, Madsen J, Munro B, et al: Idiopathic syrinx in the pediatric population: a combined center experience. J Neurosurg Pediatr 7:30-36, 2011

11. Oldfield EH, Muraszko K, Shawker TH, Patronas NJ: Pathophysiology of syringomyelia associated with Chiari I malformation of the cerebellar tonsils. Implications for diagnosis and treatment. J Neurosurg 80:3-15, 1994

12. Rocque BG, George TM, Kestle J, Iskandar BJ: Treatment practices for Chiari malformation type I with syringomyelia: results of a survey of the American Society of Pediatric Neurosurgeons. J Neurosurg Pediatr 8:430-437, 2011

13. Singhal A, Bowen-Roberts T, Steinbok P, Cochrane D, Byrne AT, Kerr JM: Natural history of untreated syringomyelia in pediatric patients. Neurosurg Focus 31(6):E13, 2011

14. Strahle J, Muraszko KM, Garton HJ, Smith BW, Starr J, Kapurch JR II, et al: Syrinx location and size according to etiology: identification of Chiari-associated syrinx. J Neurosurg Pediatr 16:21-29, 2015

15. Tokunaga M, Minami S, Isobe $\mathrm{K}$, Moriya $\mathrm{H}$, Kitahara $\mathrm{H}$, Nakata Y: Natural history of scoliosis in children with syringomyelia. J Bone Joint Surg Br 83:371-376, 2001

16. Tomlinson RJ Jr, Wolfe MW, Nadall JM, Bennett JT, MacEwen GD: Syringomyelia and developmental scoliosis. J Pediatr Orthop 14:580-585, 1994

\section{Disclosures}

The authors report no conflict of interest concerning the materials or methods used in this study or the findings specified in this paper.

\section{Author Contributions}

Conception and design: Strahle, Maher. Acquisition of data: Strahle, Starr. Analysis and interpretation of data: Strahle, Bruzek, Starr. Drafting the article: Strahle, Bruzek. Critically revising the article: Strahle, Bruzek, Garton, Maher. Reviewed submitted version of manuscript: Strahle, Bruzek. Approved the final version of the manuscript on behalf of all authors: Strahle. Statistical analysis: Strahle, Bruzek. Administrative/technical/material support: Strahle, Garton, Muraszko, Maher. Study supervision: Strahle.

\section{Correspondence}

Jennifer Strahle: Washington University School of Medicine, St. Louis Children's Hospital, St. Louis, MO. strahlej@wustl.edu. 